\title{
Improbidade Administrativa: Imprescritibilidade da Ação de Ressarcimento
}

\author{
Administrative Misconduct: Indemnity of Reimbursement Action
}

\author{
Ricardo da Silva ${ }^{a}$; Rodolfo Mota da Silva*a

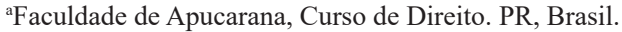 \\ *E-mail: rodolfo.mota@fap.com.br
}

\begin{abstract}
Resumo
O presente trabalho tem como escopo central trazer à lustre os aspectos relevantes da improbidade administrativa, perpassando, para tanto, dentro da conceituação basilar da boa conduta na administração pública, bem como analisando os danos causados pela corrupção, passando por fim, à análise dos consectários da conduta proba, ramo tão extenso e rico do direito administrativo, dentre as ramificações da probidade, haverá enfoco especial na imprescritibilidade da ação de ressarcimento, a qual será devidamente apresentado, conceituado, discutido e, por fim, será apresentado como os tribunais superiores vêm entendendo a matéria, para que assim haja um crescimento intelectual e doutrinário acerca do tão complexo e atraente tema. Ter-se-á como legislação basilar a Lei de Improbidade Administrativa Lei no 8.429/1992, tal como entendimentos doutrinários, os quais serão, sempre que cabível, extraídos da Carta Magna de 1988, para então encontrar o ponto de consenso sobre o tema.
\end{abstract}

Palavras-chave: Improbidade Administrativa. Corrupção. Prescritibilidade. Ação de ressarcimento.

\begin{abstract}
The presente work has as its central goal to bring the light of a relevant aspects of administrative improbity, going through the base conceptuazation of good conduct in public administration, as well as analyzing the damage caused by corruption, and finally to the analysis of the consequences of honest conduct so extensive and rich branch of administrative law, among the branches of probity there will be a special focus on the imprescritibility of the compensation action, which will be duly presented, conceptualized, discussed and, finally, it will be presented how the high Court and Supreme Court have understood the matter, so that there will be an intelectual and doctrinal growth on the complex and attactive subject. As a basic legislation, the Law of Administrative Improbity Law no 8.429/1992 and some doctri-nal understandings will be drawn, where appropriate, from the Constitution of 1988, to find the point of consensus on the subject.
\end{abstract}

Keywords: Administrative Improbity. Corruption. Imprescriptibility. Action for compensation.

\section{Introdução}

Esse trabalho surgiu com o intuito de aprofundar no assunto, e buscar respostas do porquê ocorrem constantes e corriqueiras notícias sobre o cometimento da ação de Improbidade Administrativa, elencado ao fato da prescrição punitiva. Por isso, a abordagem sobre a Imprescritibilidade da Ação de Ressarcimento. Nesse sentido, caso aja a prescrição, pode aparentar-se uma certa fragilidade do poder estatal em executar a função punitiva, entre as quais, a restauração dos danos causados pelas ações de improbidade administrativa.

Num primeiro exame, improbidade administrativa teria o sentido de desonestidade no trato da coisa pública ou na gestão do patrimônio público.

O fundamento constitucional do combate à improbidade administrativa está erigido no art. 37, $\S 4^{\circ}$, da Carta Magna de 1988. Como se vê, a Constituição Federal - CF não conceituou improbidade administrativa, limitando-se a prever algumas das punições possíveis de serem aplicadas aos ímprobos. (BRASIL, 1988).

\section{Desenvolvimento}

\subsection{Discussão}

Etimologicamente, o vocábulo "probidade", do latim probitate, significa aquilo que é bom, relacionando-se diretamente à honradez, à honestidade e à integridade. A improbidade, ao contrário, deriva do latim improbitate, que significa imoralidade, desonestidade ${ }^{1}$.

Segundo Moraes (2017), o Direito pátrio, pelos estudiosos e a atual legislação, deu alguma configuração à improbidade administrativa, procurando até mesmo demonstrar que comportamentos dessa natureza estariam a merecer sanções. Mas foi a Constituição de 1988 que categoricamente estabeleceu princípios e normas pertinentes à moralidade e à improbidade administrativas.

$\mathrm{O}$ art. $37 \mathrm{da} \mathrm{CF}$, consignou a moralidade como princípio expresso da Administração Pública. Nesse mesmo artigo, no parágrafo $\S 4^{\circ}$, por sua vez, sentenciou que a improbidade administrativa produziria vários efeitos sancionatórios, como a suspensão dos direitos políticos, a perda da função pública,

1 Significados. Probitate e improbitate. Disponível em: <https://www.significados.com.br>. 
a indisponibilidade dos bens e o ressarcimento ao erário. (BRASIL, 1988).

Nesse diapasão, segundo Emerson Garcia (2014), entende que não foi difícil perceber que o Constituinte, cansado de constatar os numerosos abusos de poder e o enfrentamento, nem sempre frutífero, dos comportamentos ímprobos, exortou a sociedade num todo, administrados e Administração, a adotar postura de maior dignidade e a afastar-se dos terrenos lamacentos onde ela própria se encontrava maculada. E foi com lastro nos parâmetros constitucionais que veio a lume a Lei $n^{\circ}$. 8.429, de 2/6/1992, Lei de Improbidade Administrativa - LIA $^{2}$ em ordem a regular, com maior minúcia, os casos de improbidade, os autores, as sanções, as providências processuais, o ressarcimento ao erário entre outros.

De acordo com Carvalho Filho (2016, p.95),

improbidade é o antônimo e significa a inobservância desses valores morais, retratando comportamentos desonestos, despidos de integridade e usualmente ofensivos aos direitos de outrem. Entre todos, um dos mais graves é a corrupção, em que o beneficiário se locupleta às custas dos agentes públicos e do Estado.

O assunto improbidade administrativa é muito extenso e abrange conceitos e ideias que acabam por se confundir com a ideia e visão da sociedade, por isso faz-se necessário sanar algumas dúvidas substanciais dentre elas, saber se improbidade administrativa é o mesmo que corrupção. A ideia de corrupção que a sociedade guarda é muito ampla e trata principalmente da má utilização da função pública em benefício próprio baseando-se nessa ideia, é perceptível atos de corrupção dentro da lei de improbidade administrativa, mas que não constitui improbidade em si.

$\mathrm{O}$ ponto mais polêmico parece ser o que se refere a imprescritibilidade da ação de ressarcimento. A prescrição é o instituto que representa a perda da possibilidade de formulação de pretensões, em razão da inércia do interessado. Os prazos prescricionais para propositura da ação de improbidade administrativa encontram-se previstos no art. $23^{3}$ da Lei 8.429/1992, alterado pela Lei 13.019/2014

No entanto, a partir da legislação vidente, os prazos prescricionais não são uniformes nas ações de improbidade, variando de acordo com a qualidade do sujeito ativo, réu na respectiva ação judicial.

Desse modo, segundo Capez (2015, p.148)

Quando se fala em prescritibilidade das sanções previstas na Lei de Improbidade Administrativa, a primeira coisa que se deve ter em mente é a disposição do art. $37, \S 5^{\circ}$, da Constituição Federal, que estabelece a imprescritibilidade das ações que visam o ressarcimento do erário por atos ilícitos que lhe causem prejuízo, seja de parte de servidor seu ou não.

De plano, é mister destacar que o dispositivo, na parte em que trata da imprescritibilidade, alude à pretensão ressarcitória do Estado contra o agente, servidor ou não, que lhe causou danos em razão da prática de ato ilícito. Não custa lembrar que a pretensão de ressarcimento de danos se situa dentro das ações indenizatórias, e isso porque, em última análise, visa à reparação dos danos causados pela conduta ilícita.

\section{Conclusão}

O STF reconhece a imprescritibilidade de ação de ressarcimento decorrente de ato doloso de improbidade. Os ministros do STF decidiram no Recurso Extraordinário RE $852.475^{5}$, que não há prazo para cobrança na Justiça de dinheiro público desviado de forma dolosa. Por 6 votos a 5, ministros da corte decidiram que as ações que pedem ressarcimento aos cofres públicos por atos de improbidade cometidos de forma intencional não prescrevem.

Com o voto de Marco Aurélio, para ele o prazo de cinco anos previsto na LIA deve ser respeitado. Já o ministro Celso de Mello, disse que todos os agentes públicos são responsáveis perante a lei, o decano ao votar para que casos de improbidade não prescrevam, destacou que o maior interesse deve ser o da moralidade. A ministra Carmem Lúcia, também votou para não ter prazo para o Estado entrar com ações de pedidos de ressarcimento imprescritibilidade.

Os ministros Luiz Fux e Luís Roberto Barroso, que tinham votado recentemente para se estabelecer um prazo, pediram para reajustar os votos, após a análise, ambos chegaram à conclusão de que atos de improbidade dolosos, ou seja, quando há a intenção de prejudicar o Estado não devem prescrever.

Acerca da imprescritibilidade da ação de ressarcimento, é possível afirmar que se trata de um dever reparação e preservação do erário, pois poderá ser reposto aos cofres

2 Disponível em: < http://www.planalto.gov.br/ccivil_03/leis/L8429.htm>.

3 Art. 23. As ações destinadas a levar a efeitos as sanções previstas nesta lei podem ser propostas:

I - até cinco Anos após o término do exercício de mandato, de cargo em comissão ou de função de confiança;

II - dentro do prazo prescricional previsto em lei específica para faltas disciplinares puníveis com demissão a bem do serviço público, nos casos de exercício de cargo efetivo ou emprego;

III - até cinco anos da data da apresentação à administração pública da prestação de contas final pelas entidades referidas no parágrafo único do art. $1 .^{\circ}$ desta Lei.

4 Disponível em: <http://www.planalto.gov.br/ccivil_03/_Ato2011-2014/2014/Lei/L13019.htm>.

5 STF reconhece imprescritibilidade de ação de ressarcimento decorrente de ato doloso de improbidade. O Tribunal, por maioria, apreciando o tema 897 da repercussão geral, deu parcial provimento ao recurso para afastar a prescrição da sanção de ressarcimento e determinar o retorno dos autos ao tribunal recorrido para que, superada a preliminar de mérito pela imprescritibilidade das ações de ressarcimento por improbidade administrativa, aprecie o mérito apenas quanto à pretensão de ressarcimento. Vencidos os Ministros Alexandre do Moraes, Dias Toffoli, Ricardo Lewandowski, Gilmar Mendes e Marco Aurélio. O Tribunal fixou a tese de que são imprescritíveis as ações de ressarcimento ao erário fundadas na prática de ato doloso tipificado na Lei de Improbidade Administrativa (8/8/2018). Disponível em: http:/www.stf.jus.br/portal/jurisprudenciaRepercussao/verAndamentoProcesso.asp?inciden-te $=4670950 \&$ numeroProcesso $=852475 \&$ classeProcesso $=$ RE \&numeroTema $=897 \#$. 
públicos bens e recursos que antes era composto ao patrimônio público.

Dos corolários apresentados, pode-se aferir que a ideia principal do instituto é evitar a dilapidação do patrimônio público, assim como a rejeição da omissão do Estado contra os atos ilícitos praticados pelo ocupante de cargo, emprego ou função pública em detrimento do erário.

Destarte, foi possível verificar que a probidade administrativa, juntamente com seus corolários são de extrema relevância, posto que devem ser respeitados nos mais diversos órgãos administrativos existentes, sendo vedado a corrupção ao que se espera dos agentes públicos a execução de suas funções com a devida honestidade e comportamentos que podem assegurar segurança jurídica, e a eficiência no manuseio da máquina pública.

Por todo o exposto, teve-se a consciência da abrangência e repercussão desta figura consectária da improbidade administrativa e a imprescritibilidade da ação de ressarcimento ao erário, visto os constantes casos de corrupção e improbidade que são anunciados em diferentes mídias sociais.

Por fim, tem-se que o tema abordado é de relevante importância social e jurídica, demonstrando ser a improbidade administrativa e seus corolários, em especial a imprescritibilidade da ação de ressarcimento, norma de caráter cogente e com roupagem principiológica, atribuindo assim importância especial ao tema proposto.

\section{Referências}

BRASIL. Constituição da República Federativa do Brasil: promulgada em 5 de outubro de 1988.

CARVALHO FILHO, J.S Improbidade administrativa: prescrição e outros prazos extintivos. São Paulo: Atlas, 2016.

CAPEZ, F. Improbidade administrativa: limites constitucionais à lei de improbidade. São Paulo: Saraiva, 2015.

GARCIA, E, Improbidade administrativa. São Paulo: Saraiva, 2014.

MORAES, A. Direito Constitucional. São Paulo: Atlas, 2017.

STF - Supremo Tribunal Federal. Relator Ministro Alexandre de Moraes. Recurso Extraordinário RE 852245 SP- São Paulo. 2018. Disponível em: <http://www.stf.jus.br/portal/jurisprudenciaRepercussao/verAndamentoProcesso.asp? incidente $=4670950 \&$ numeroProcesso $=852475 \&$ classeProcesso $=$ RE \&numeroTe$\mathrm{ma}=897 \#>$. Acesso em: 10 abr. 2019.

STF - Supremo Tribunal Federal. Lei $n^{\circ} 8.429$, de 2 de junho de 1992. Disponível em: <http://www.planalto.gov.br/ccivil 03/ LEIS/L8429.htm>. Acesso em: abr. 2019.

STF - Supremo Tribunal Federal. Constituição Federal. Disponível em: $\quad<$ http://www.planalto.gov.br/ccivil_03/constituicao/ constituicaocompilado.html>. Acesso em: 14 mar. 2019. 